
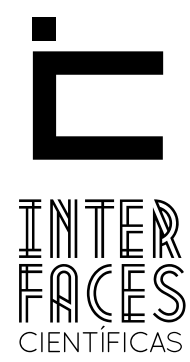

DIREITO

\title{
APLICAÇÃO DA FORENSE DIGITAL NA JUSTIÇA DO TRABALHO
}

Rodrigo Grazinoli Garrido ${ }^{1}$

\section{RESUMO}

A complexidade das relações sociais alcançou o mundo virtual. 0 uso de equipamentos digitais e o acesso à rede mundial de computadores é feito praticamente por todos, sobretudo no mundo do trabalho. Para regular estas relações, busca-se estabelecer o marco civil da internet e tipificar crimes cibernéticos. Quando o mau uso ocorre no ambiente ou nas relações de trabalho pode ensejar dispensa por justa causa, além de gerar responsabilização pelos danos materiais e morais decorrentes da conduta. Entretanto, para o convencimento do julgador, muitas vezes, há necessidade da elaboração de um laudo pericial. Assim, buscou-se demonstrar a importância da prova forense digital para questões trabalhistas. Constatou-se que as empresas têm monitorado as ferramentas de trabalho digitais e reconhecido mau uso pelo empregado. A prova técnica para a materialização pode ser suprida pela prova advinda da esfera criminal, uma vez que muitas destas ações ensejaram, também, ações penais.

\section{PALAVRAS-CHAVE}

Forense Digital. Crimes Cibernéticos. Prova Científica. Ciência Forense. Justiça do Trabalho. 


\section{ABSTRACT}

The complexity of social relations reached the virtual world. The use of digital equipment and the access to the world wide web is done by virtually everyone, especially in the workplace. To regulate these relations, we seek to establish the civil framework of the Internet and criminalizing cyber crimes. When the misuse runs the environment or working relationships can give rise to dismissal for just cause, and generate accountability for material and moral damages arising from the conduct. However, for the conviction of the judge often no need to draw up an expert report. Thus, we sought to demonstrate the importance of digital forensic evidence to labor issues. It was found that the companies have been monitoring the digital working tools and recognized misuse by the employee. The technical test for the materialization can be supplied by the evidence arising from the criminal sphere, since many of these actions also gave rise to criminal proceedings.

\section{KEYWORDS}

Digital Forensics. Cybercrime. Scientific Evidence. Forensic Science. The Labor Justice.

\section{RESUMEN}

La complejidad de las relaciones sociales alcanzó el mundo virtual. El uso de dispositivos digitales y el acceso a la red mundial de computadoras se hace por prácticamente todo el mundo, especialmente el mundo del trabajo. Para regular estas relaciones, buscamos establecer marco civil tipificando los internautas y ciber crímenes. Cuando el abuso se ejecuta en el entorno o las relaciones de trabajo puede dar lugar el despido por justa causa, y generar la responsabilidad por los daños materiales y morales causados por la conducta. Sin embargo, para la convicción del juez a menudo sin necesidad de preparar un informe técnico. Por lo tanto, hemos tratado de demostrar la importancia de las pruebas forenses digitales para cuestiones laborales. Se encontró que las empresas han monitoreado las herramientas de trabajo digital y reconocido por el mal uso de los empleados. La técnica de la prueba para la materialización puede ser suministrada por la evidencia que surge de la esfera penal, ya que muchas de estas acciones también dieron lugar a procesamientos.

\section{PALABRAS CLAVE}

Análisis Forense Digital; Delitos Cibernéticos; Prueba Científica; la Ciencia Forense; El Tribunal del Trabajo. 


\section{INTRODUCÇÃO}

A complexidade das relações sociais já não se restringe ao mundo físico, alcançando o virtual (digital). Pode-se considerar que o uso de equipamentos digitais e o acesso rede mundial de computadores com troca de informações está completamente disseminado, sobretudo no mundo do trabalho.

Nesse contexto, que se busca determinar o marco civil da internet, buscando limitar o mau uso da rede mundial e dar segurança à informação. Em complementaridade, já são tipificados uma gama de crimes cibernéticos, relacionados p.ex. à invasão de privacidade, descumprimentos de contratos celebrados pela internet, disseminação de e-mails caluniosos ou difamatórios, pornografia infantil, cyberbulling, compartilhamento ilícito de software, músicas e filmes.

Quando o mau uso corre no ambiente ou nas relações de trabalho pode ensejar a dispensa por justa causa, além de atribuir ao usuário a responsabilização pelos danos materiais e morais oriundos dessa conduta. Entretanto, para dar materialidade a tais atos e auxiliar no convencimento do julgador em litígios digitais, face à complexidade do tema, na maioria das vezes, há necessidade da elaboração de um laudo pericial realizado por um expert.

Com isso, por meio de pesquisa exploratória e descritiva, desenvolvida a partir de documentação indireta de fontes primárias e secundárias, buscou-se demonstrar a importância da prova técnica produzida por meio de conhecimentos da forense digital para as questões trabalhistas.

\section{A PROVA TÉCNICA}

Theodoro Jr. (2012) define prova técnica, ou pericial, como sendo "o meio de suprir a carência de conhecimentos técnicos de que se ressente o juiz para apuração dos fatos litigiosos”. Em continuidade, a perícia seria a diligência realizada por pessoa física, o perito, no intuito de analisar tecnicamente um fato e instruir o procedimento legal (FILHO, 2009).

Assim, a prova pericial é, esencialmente, técnico-científica e produzida por uma diversidade de conhecimentos requeridos de acordo com o objetivo do exame e da natureza do fato e das evidências deixadas após este. Todavia, pode-se definir que a prova pericial é produzida no âmbito da Ciência Forense, pois segundo Gialamas (2000), tal ciência é originada da aplicação do saber científico humano à matéria ou aos problemas do Direito nos seus diversos ramos.

Entre os saberes aplicados na produção da prova técnica, aqueles relacionados à informática têm despontado na atualidade. Certamente, esta valorização se deve a uma transferência para o mundo virtual (digital) de várias relações sociais, como as relacionadas ao trabalho. Assim, como observado por Garrido e Giovaneli (2012, p. 165):

Problemas tais como a invasão de privacidade, descumprimentos de contratos celebrados pela internet, disseminação de e-mails caluniosos ou difamatórios, pornografia infantil, cyberbulling, compartilhamento ilícito de software, músicas e filmes, entre outros, passaram a fazer parte da nova realidade vivida pela sociedade brasileira e mundial.

Quanto aos métodos de coleta de dados na pericia digital existem dois tipos: a Live Forensics ou a Post Mortem Forensics (DELLA VECCHIA, 2010). Na primeira metodologia a perícia é feita no equipamento ainda em funcionamento, permitindo a obtenção de dados voláteis. Contudo, é mais utilizada a metodologia de Post Mortem Forensics, que trata do exame realizado após o desligamento do equipamento.

\section{MARCO CIVIL DA INTERNET E CRIMES CIBERNÉTICOS}

Ao falar de implicações do mundo digital nas relações sociais, é necessário tecer alguns comentários sobre 
o marco civil da internet (Lei 12.965, de 23 de abril de 2014). Esta norma estabelece princípios, garantias, bem como direitos e deveres aos usuários da internet no Brasil, verificando-se a inserção de uma gama protetória ao usuário quanto à sua privacidade em acesso a tal sistema.

O marco civil da internet assegura a intimidade dos dados particulares e somente por meio de uma ordem judicial é que uma notícia ou conteúdo supostamente ofensivo, lançado na rede mundial de computadores será retirado por ferir a intimidade ou dignidade da pessoa humana, uma vez que a ponderação de valores será a técnica necessária ao Juiz quando houver conflitos entre os princípios da liberdade de expressão com o do sigilo da intimidade e de correspondência como assegurados na ordem constitucional.

A parte interessada poderá requerer ao juiz que ordene a entrega dessas informações para fins de fazer prova em processo cível, penal e ainda no processo do trabalho. No entanto, a obtenção e interpretação destes dados muitas vezes demanda análise pericial.

Por vezes, o uso indevido da informática enseja crimes cibernéticos, como os crimes contra a propriedade artística e intelectual previstos no art. 184 do CP e Lei 9609/98; os relativos às fraudes bancárias relacionados aos artigos $155, \S \S 3^{\circ}$ e $4^{\circ}$, II, e 171 do CP; aqueles onde aparece a pornografia infantil, como os insertos nos art. 241 e 241-A da Lei 8069/90; os crimes entendidos como Cyberbulling onde ocorre a criação e publicação de perfis falsos ou ofensas em blogs e facebook, sendo crimes contra a honra enquadrados nos artigos 138, 139, 140 do CP. Contudo, em muitas situações estes desvios ocorrem no ambiente de trabalho, tendo como autores o empregado e o empregador.

Além disso, a Lei 9.396, de 24 de julho de 1996, trata da interceptação de comunicações telefônicas e no parágrafo primeiro do artigo $1^{\circ}$, estabelece que também será aplicada à interceptação do fluxo de comunicações em sistemas de informática e telemática. Já a Lei 12737, de 30 de novembro de 2012, inseriu no Código penal a tipificação criminal de delitos informáticos. Internacionalmente, o Conselho da Europa, além da África do Sul, Estados Unidos, Canadá e Japão, celebraram a Convenção sobre o Cibercrime, tratando de uma política criminal comum com o objetivo de proteger a sociedade.

\section{APLICAÇÃO DA FORENSE DIGITAL NAS AÇÕES TRABALHISTAS}

A constituição Federal estabelece o direito à intimidade e o sigilo das correspondências ${ }^{2}$, aplicáveis no âmbito das relações de emprego quer em meio físico ou no virtual, tais como e-mails dos empregados acessados em máquinas do empregador. Por outro lado, a prática revela que inúmeras empresas fornecem aos empregados e-mail para o trabalho denominado de "e-mail corporativo", havendo um consenso parcial sobre a possibilidade do empregador, por meio de seu poder hierárquico, monitorá-los para fins de melhor conduzir sua atividade empresarial e se precaver de responsabilidades frente a terceiros em razão de danos causados pelo empregado.

Sobre a possibilidade de se monitorar ou pesquisar e-mails corporativos em caso de eventual conteúdo indevido na internet ou mensagem que possa causar constrangimentos e efetivo reparo à honra do ofendido, a doutrina trabalhista tem assim se posicionado:

[....] 0 caso em espécie é de descoberta acidental pelo empregador que a Autora cometera falta gravíssima, contrariando expresso dispositivo do contrato de trabalho, avençado por escrito, e repassava segredos comerciais da Reclamada para empresa concorrente. [...] Como assistente de importação e exportação detinha conhecimentos de segredos estratégicos e táticos da empresa. E tinha compromisso expresso de sigilo. $\mathrm{E}$

2. Constituição Federal de 1988, Art. $5^{\circ}$. CF: X - são invioláveis a intimidade, a vida privada, a honra e a imagem das pessoas, assegurado o direito a indenização pelo dano material ou moral decorrente de sua violação; [...] XII - é inviolável o sigilo da correspondência e das comunicações telegráficas, de dados e das comunicações telefônicas, salvo, no último caso, por ordem judicial, nas hipóteses e na forma que a lei estabelecer para fins de investigação criminal ou instrução processual penal. 
de tanto não se preocupou ao ceder, sem permissão, os dados que dispunha em razão do cargo ocupado. [...] Com os fundamentos supra dou provimento ao apelo da Reclamada para considerar justa a demissão tendo em vista a gravidade da falta cometida. [...] (TST, Rel. Maria de Assis Calsing, Ag. Instr. em RR n ${ }^{\circ}$ 2771/2003262-02-40, Julgado em 02/04/2008).

Quanto à possibilidade de se estabelecer quais sítios podem ser acessados no ambiente de trabalho, a jurisprudência vem sedimentando conteúdo:

RITO SUMARÍSSIMO. RECURSO ORDINÁRIO. JUSTA CAUSA. ART. 482, "b”, DA CLT. Burla de regras da empresa para acesso a sítios, o que era vedado. Norma regulamentar da qual o reclamante tinha conhecimento prévio. Computador e internet, instrumentos de trabalho utilizados irregularmente, para uso pessoal. Incontinência de conduta e mau procedimento. Falta grave que está caracterizada. (TRT02, Relatora Maria Aparecida Duenhas, RO $\mathrm{n}^{\circ}$. 01875200843102004, Julgado em 17/02/2009).

Verifica-se, no entanto, que apesar de certa pacificidade sobre o tema, podem ser encontradas vozes em sentido contrário à possibilidade do empregador manter vigilância nesse ambiente de trabalho, em tais correspondências eletrônicas ou mesmo à restrição de alguns sítios que podem danificar os equipamentos eletrônicos da empresa.

Ademais, o certo é que o empregador necessitará provar em juízo que eventual empregado se utilizou de seu e-mail ou equipamentos da empresa para cometer um ilícito capaz de lhe garantir, não somente a responsabilização civil do empregado, mas também a sua dispensa por justa causa nos termos das alíneas "b" ou "h" do artigo 483 da CLT.

Desta forma, será necessário realizar uma perícia digital em seus equipamentos. Havendo êxito nessa prova, o empregado irá indenizar o empregador nos próprios autos trabalhistas, se efetivamente antecipou esses honorários periciais a despeito da CLT entender que não se pode exigir tal pagamento antes da realização da prova peri- cial, pois o artigo 790-B desse diploma afirma que a responsabilidade pelo pagamento dos honorários periciais é da parte sucumbente na pretensão objeto da perícia, salvo se beneficiária de justiça gratuita.

Considerando que eventual conduta do empregado poderá ser considerada crime e havendo a comunicação à autoridade policial, bem como instaurado o procedimento cabível para isto, será possível, também, ao Julgador valer-se da prova pericial produzida nos autos de um processo criminal ou mesmo valer-se da decisão de tal juízo que tenha determinado o autor do fato como sendo o empregado pelo ato criminoso, havendo menos custos ao empregador quando seu advogado porventura solicitar a suspensão ${ }^{3}$ do processo trabalhista para se aguardar o laudo pericial ou a conclusão do processo criminal.

Assim, o julgador poderá, também, sobrestar o andamento da ação trabalhista para que seja resolvida a materialidade e quem cometeu eventual crime cibernético. Comprovada a conduta e quem produziu esse crime, o julgador poderá acolher a justa causa alegada na defesa ou mesmo produzida em uma ação do empregador em face do empregado, quando se discute a indenização de danos material ou moral à empresa ${ }^{4}$.

A prova pericial computacional na Justiça do Trabalho, também, tem sido utilizada para a rejeição do depoimento testemunhal quando o depoente apresentar estreita amizade com o autor comprovada por meio das redes sociais da internet, como por exemplo, comentários e fotos no Facebook ${ }^{5}$. No entanto, o tema ainda é altamente complexo, chegando o TST a não acolher o argumento de que conversas no Facebook poderiam

3. CPC, Art. 265. Suspende-se o processo: (...)V - quando a sentença de mérito: a) depender do julgamento de outra causa, ou da declaração da existência ou inexistência da relação jurídica, que constitua o objeto principal de outro processo pendente.

4. STJ Súmula no 227 - Pessoa Jurídica - Dano Moral. A pessoa jurídica pode sofrer dano moral. 5. PROCESSO: RO. no. 0000962-92.2012.5.01.0246, julgado em 11.12.2013, $2^{\mathrm{a}}$ Turma do TRT $1^{\mathrm{a}}$ região. 
caracterizar amizade íntima capaz de fazer com que determinada testemunha fosse dispensada de seu mister ${ }^{6}$.

\section{CONCLUSÃO}

Diante da variedade de opções de acesso a sites da rede mundial de computadores, inclusive, de utilização indevida do e-mail corporativo, ou seja, o fornecido como ferramenta de trabalho, as empresas passaram a monitorar essas ferramentas de trabalho, chegando por vezes a dispensar o empregado por justa causa em razão de conteúdos indevidos lançados nessa rede ou quando esse produziu um ato considerado como crime cibernético utilizando-se das máquinas do empregador. Devido à complexidade de tema, a prova da materialidade de tais atos, na maioria das vezes, há necessidade da elaboração de um laudo pericial realizado por um expert, podendo, no entanto, na Justiça do Trabalho ser utilizado como prova aquele laudo advindo da esfera criminal, sem custos às partes numa eventual reclamação trabalhista.

\section{REFERÊNCIAS}

DELLA VECCHIA, E. Investigação Digital: Conceitos, Ferramentas e Estudos de Caso. III Congresso tecnológico (INFOBrasil), 2010, Fortaleza. Anais do III Congresso Tecnológico, 2010.

FILHO. M.A.T. Curso de Direito Processual do Trabalho. Processo de Conhecimento - 2. LTr., v.II., fev. 2009, p.1133.

GARRIDO, R.G. e GIOVANELLI. Ciência Forense. Uma introdução à criminalística. FAPERJ, 2012.

GIALAMAS D.M. Criminalistics. In: Siegel J, Knupfer G, Saukko P, editors. Encyclopedia of forensic sciences. Amsterdam: Elsevier, 2000, p.471-447.

THEODORO Jr., H. Teoria Geral do Direito Processual Civil I. 53.ed. Rio de Janeiro: Forense, 2012.

6. PROCESSO No TST-RR-628-67.2011.5.12.0026 “Não obstante as alegações da empresa-recorrente, da v. decisão do e. Tribunal Regional, não há como se extrair que a amizade íntima entre a empregada e a testemunha, consubstanciadas em cópias de comunicações eletrônicas (Facebook), tenha o condão de demonstrar que realmente havia relação de amizade íntima entre elas ao ponto de desencadear a não isenção de ânimo que caracteriza a testemunha suspeita. E se enveredássemos pelo campo que deseja a empresa-recorrente, fatalmente reexaminaríamos matéria de cunho factual, já analisada e decidida pelas instâncias ordinárias." 
Recebido em: 25 de Janeiro 2015

Avaliado em: 26 de Janeiro 2015

Aceito em: 30 de Janeiro 2015
1. Biomédico; MSc; DSc; Perito Criminal IPPGF/PCERJ; Professor do Mestrado em Direito UCP e Professor Adjunto FND/UFRJ. E-mail: grazinoli. garrido@gmail.com

2. Advogado; Especialista em Direito do Trabalho, Processo do Trabalho e Direito Constitucional; Mestrando em Direito - UCP. E-mail: adjoseluis@live.com 